\title{
A 2008 Questionnaire-Based Survey of Gastroesophageal Reflux Disease and Related Diseases by Physicians in East Asian Countries
}

\author{
Yasuhiro Fujiwara $^{f}$ Shin-ichi Takahashi ${ }^{g}$ Tetsuo Arakawa $^{f}$ Jose D. Sollano ${ }^{\text {a }}$ \\ Qi Zhu ${ }^{b}$ Udom Kachintornc Abdul Aziz Rani ${ }^{d}$ Ki-Baik Hahm ${ }^{\text {e }}$ Takashi Joh ${ }^{\text {h }}$ \\ Yoshikazu Kinoshitai Takayuki Matsumoto ${ }^{j}$ Yuji Naito $^{k}$ Koji Takeuchil Kenji Furuta ${ }^{i}$ \\ Akira Terano $^{m}$ the IGICS Study Group

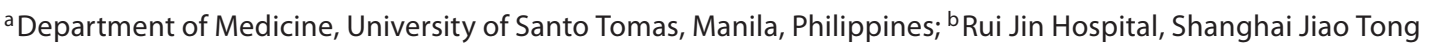
University School of Medicine, Shanghai, China; ' Division of Gastroenterology, Department of Internal Medicine, Faculty of Medicine, Siriraj Hospital Mahidol University, Bangkok, Thailand; d Department of Internal Medicine, Faculty of Medicine, University of Indonesia Cipto Mangunkusumo Hospital and Indonesian University School of Medicine, Jakarta, Indonesia; ' Lee Gil Ya Cancer and Diabetes Institute, Gachon University of Medicine and Science, Incheon, Korea; ${ }^{f}$ Department of Gastroenterology, Osaka City University Graduate School of Medicine, Osaka, ${ }^{9}$ Department of Gastroenterology, Kyorin University School of Medicine, Tokyo, ${ }^{\mathrm{h}}$ Department of Gastroenterology and Metabolism, Nagoya City University Graduate School of Medical Sciences, Nagoya, iDepartment of Gastroenterology and Hepatology, Shimane University School of Medicine, Izumo, jDivisions of Lower Gastroenterology, Department of Internal Medicine, Hyogo College of Medicine, Nishinomiya, ${ }^{k}$ Department of Molecular Gastroenterology and Hepatology, Kyoto Prefectural University of Medicine, Kyoto, 'Division of Pathological Sciences, Department of Pharmacology and Experimental Therapeutics, Kyoto Pharmaceutical University, Kyoto, 'm Dokkyo Medical University, Mibu, Shimotsuga, Japan
\end{abstract}

\section{Key Words}

Gastroesophageal reflux disease - Barrett's esophagus • Esophageal adenocarcinoma $\cdot$ Nonerosive reflux disease $\cdot$ Proton-pump inhibitor $\cdot$ Heartburn

\footnotetext{
Abstract

Background/Aims: Gastroesophageal reflux disease (GERD) is a common gastrointestinal disease. This study was designed to examine current epidemiology, diagnosis, management, and treatment of patients diagnosed with GERD by surveying physicians in several East Asian countries. Methods: A questionnaire-based survey was completed in six countries including China, Indonesia, Japan, Korea, the Philippines, and Thailand between July 2008 and December 2008. Results: In total, 876 physicians participated in the
}

study. Most physicians in all countries, except Japan, frequently used international guidelines for the care of GERD patients, whereas approximately half of Japanese physicians did not use such guidelines. GERD was common among many patients, but Barrett's esophagus, particularly the long-segmental type, was rare. The incidence of esophageal cancer, particularly adenocarcinoma, was high in China, but low in other countries. Most physicians diagnosed GERD based on symptoms, followed by endoscopy in Japan and Korea, or in other countries, by the proton-pump inhibitor (PPI) test. Heartburn was recognized as the chief complaint in all countries except Korea. Most physicians in all countries used PPI as the first-line of treatment for GERD. Increasing the PPI dose was the treatment of choice for PPI-refractory erosive esophagitis in Korea, the Philippines, and Thailand. In contrast, in other countries, physicians used a combina-

\section{KARGER}

Fax +41613061234 E-Mail karger@karger.ch www.karger.com
(C) 2009 S. Karger AG, Basel 0012-2823/09/0802-0119\$26.00/0 www.karger.com/dig
Yasuhiro Fujiwara, MD

Department of Gastroenterology

Osaka City University Graduate School of Medicine

1-4-7 Asahimachi, Abenoku, Osaka 545-8585 (Japan)

Tel. +81 66645 3811, Fax +81 66645 3813,E-Mail yasu@med.osaka-cu.ac.jp 
tion of PPI and other drugs to treat PPI-refractory erosive esophagitis. Prescription of antidepressant drugs increased for PPI-refractory nonerosive reflux disease compared with PPI-refractory erosive esophagitis. Conclusion: The findings in the present survey are useful to understand the current epidemiology, diagnosis, and treatment of GERD in East Asian countries.

Copyright ๑ 2009 S. Karger AG, Base

\section{Introduction}

Gastroesophageal reflux disease (GERD), and other related diseases, are caused by abnormal reflux of gastric contents into the esophagus. GERD is a common gastrointestinal (GI) disease in Western countries, as well as in Asia $[1,2]$. GERD is divided into two subtypes: erosive esophagitis and nonerosive reflux disease (NERD; defined as troublesome reflux symptoms without a break in the esophageal mucosa upon endoscopy) [3, 4]. Barrett's esophagus and esophageal adenocarcinoma are proposed to be GERD-related diseases [4], but their prevalence is believed to be lower in East Asia compared with Western countries [5].

There are several national and international guidelines for GERD diagnosis and management, such as the Asian-Pacific consensus [3], the Montreal definition [4], and the ACG guidelines [5]. These guidelines, textbooks, medical journals, and symposia or lectures, may affect the decisions that physicians make regarding the diagnosis and treatment of GERD. However, current epidemiology, diagnosis, management, and treatment of patients diagnosed with GERD and other related diseases in East Asian countries are not well known.

Using a questionnaire-based survey, we examined various aspects of GERD, as well as NERD, in East Asia. These aspects included the use of guidelines, epidemiology, diagnosis, treatment, and its relation to Barrett's esophagus and esophageal cancer. In addition, we analyzed the differences in epidemiology, diagnostic tools, and patient management that exist between countries from a physician's perspective.

\section{Subjects and Methods}

Methods

This is the second East Asian questionnaire-based survey done by the International Gastrointestinal Consensus Symposium (IGICS), which is the international section of the Japanese Gastroenterological Association. The first survey was done in
2007 and focused on the use of nonsteroidal anti-inflammatory drugs and prevention of GI damage [6]. Representative members from the IGICS committee provided a questionnaire to physicians in each country studied starting at the beginning of July 2008. Responses were collected at the end of December 2008. Each physician was asked to complete a questionnaire about GERD and its related diseases. The questionnaire focused on the following items: (1) the use of guidelines for the care of GERD patients; (2) the epidemiology of GERD, NERD, Barrett's esophagus and its subtypes, and esophageal cancer (including squamous cell carcinoma and adenocarcinoma); (3) the diagnosis of GERD and NERD, and (4) first-line treatment of erosive esophagitis, NERD, or proton-pump inhibitor (PPI)-refractory cases.

Statistical Analysis

The proportion of gastroenterologists that participated in each country was analyzed by the $\chi^{2}$ test. Differences in the prevalence of GERD patients treated, the proportion of GERD patients presenting with NERD, and the prevalence of Barrett's esophagus were compared using the Wilcoxon signed-rank test. The number of patients with esophageal cancer encountered by physicians was expressed as a median at the 25th and 75th percentiles. Differences between countries were compared using one-way ANOVA followed by the Fisher's paired least-significant difference test. Comparisons between esophageal squamous cell carcinoma and esophageal adenocarcinoma within the same country were analyzed by paired t test. $\mathrm{p}<0.05$ was considered significant.

\section{Results}

\section{Participants}

In total, 876 physicians participated in this survey. The overall completion response rate was of $74.8 \%$. Among the physicians surveyed, 625 (71\%) were gastroenterologists. In China, 158 (91\%) of the 173 respondents were gastroenterologists. Similarly, 82 (75\%) out of the 109 respondents in Indonesia were gastroenterologists, as were 126 (68\%) out of the 185 Japanese respondents, 151 (82\%) out of 184 respondents from Korea, 68 (44\%) out of 153 respondents from the Philippines, and 40 (56\%) out of 72 respondents from Thailand. A significantly higher proportion of the gastroenterologists were from China, while a lower proportion was from the Philippines.

\section{Use of Guidelines}

The guidelines used by physicians for the care of GERD patients in East Asia are shown in table 1. Overall, the most frequently used guideline used by physicians was the Asian-Pacific consensus report (33\%), followed by the Montreal definition (31\%) and the ACG guideline (20\%); $15 \%$ of physicians did not use any guidelines for the care of GERD patients. The three most frequently 
Table 1. Use of guidelines for the care of GERD patients in East Asia

\begin{tabular}{lccllcrr}
\hline & Total & $\begin{array}{l}\text { Asian-Pacific } \\
\text { consensus [3] }\end{array}$ & $\begin{array}{l}\text { Montreal } \\
\text { definition [4] }\end{array}$ & $\begin{array}{l}\text { ACG } \\
\text { guidelines [7] }\end{array}$ & $\begin{array}{l}\text { Genval } \\
\text { Workshop } \\
\text { Report [37] }\end{array}$ & Others & No use \\
\hline China & 173 & $108(62)$ & $23(13)$ & $36(21)$ & $1(1)$ & $6(3)$ & $2(1)$ \\
Indonesia & 109 & $39(36)$ & $47(43)$ & $9(8)$ & $4(4)$ & $16(15)$ & $7(6)$ \\
Japan & 181 & $17(9)$ & $40(22)$ & $18(10)$ & $3(2)$ & $5(3)$ & $100(55)$ \\
Korea & 178 & $56(20)$ & $82(46)$ & $34(19)$ & $16(9)$ & $3(2)$ & $7(4)$ \\
Philippines & 135 & $56(41)$ & $41(30)$ & $37(27)$ & $3(2)$ & $4(3)$ & $5(4)$ \\
Thailand & 71 & $23(32)$ & $30(42)$ & $34(48)$ & $0(0)$ & $1(1)$ & $9(13)$ \\
\hline Total & 847 & $279(33)$ & $263(31)$ & $168(20)$ & $27(3)$ & $35(4)$ & $130(15)$ \\
\hline
\end{tabular}

Values indicate the number (\%) of physicians using the indicated guidelines in each country.

Table 2. Prevalence of GERD patients in East Asia

\begin{tabular}{lrrrrr}
\hline & Total & \multicolumn{2}{l}{$\begin{array}{l}\text { Frequency of GERD patients among the } \\
\text { total number of patients }\end{array}$} \\
\cline { 3 - 6 } & & \multicolumn{1}{l}{$<10 \%$} & $10-25 \%$ & $25-50 \%$ & $>50 \%$ \\
\hline China & 172 & $27(16)$ & $119(69)$ & $24(14)$ & $1(1)$ \\
Indonesia & 108 & $36(33)$ & $56(52)$ & $9(8)$ & $1(1)$ \\
Japan & 183 & $124(68)$ & $51(28)$ & $6(3)$ & $2(1)$ \\
Korea & 184 & $64(35)$ & $86(47)$ & $28(15)$ & $0(0)$ \\
Philippines & 152 & $21(14)$ & $78(51)$ & $38(25)$ & $1(1)$ \\
Thailand & 72 & $29(40)$ & $29(40)$ & $12(17)$ & $0(0)$ \\
\hline Total & 871 & $301(35)$ & $419(48)$ & $117(13)$ & $5(1)$ \\
\hline
\end{tabular}

Values indicate the number (\%) of physicians in each country according to the frequency of GERD patients treated among the total number of patients.

used guidelines were similar in all five countries; however, 55\% of Japanese physicians did not use any guidelines.

\section{Epidemiology of GERD, NERD, Barrett's Esophagus,} and Esophageal Cancer

The prevalence of GERD patients among the total patients treated is shown in table 2. More than half of the physicians surveyed treated GERD patients, which accounted for $>10-25 \%$ of total patients, suggesting that GERD is a common disease in East Asian countries. A significantly lower prevalence of GERD patients was observed in Japan, yet a higher prevalence was seen in the Philippines (table 2). Analysis of the prevalence of NERD among GERD patients showed that 336 (39\%) out of 856
Table 3. Prevalence of Barrett's esophagus patients in East Asia

\begin{tabular}{lrrrrr}
\hline & Total & \multicolumn{4}{l}{$\begin{array}{l}\text { Frequency of Barrett's esophagus patients } \\
\text { among the total number of patients }\end{array}$} \\
\cline { 3 - 6 } & & $<1 \%$ & $1-5 \%$ & $5-10 \%$ & $>10 \%$ \\
\hline China & 161 & $47(29)$ & $81(50)$ & $32(20)$ & $1(1)$ \\
Indonesia & 107 & $76(71)$ & $27(25)$ & $3(3)$ & $1(1)$ \\
Japan & 179 & $104(58)$ & $54(30)$ & $10(6)$ & $11(6)$ \\
Korea & 184 & $131(71)$ & $44(24)$ & $6(3)$ & $3(2)$ \\
Philippines & 140 & $89(64)$ & $40(29)$ & $8(6)$ & $3(2)$ \\
Thailand & 70 & $40(57)$ & $30(43)$ & $0(0)$ & $0(0)$ \\
\hline Total & 841 & $487(58)$ & $276(33)$ & $59(7)$ & $19(2)$ \\
& & & &
\end{tabular}

Values indicate the number (\%) of physicians in each country according to the frequency of Barrett's esophagus patients treated among the total number of patients.

physicians answered that they observed NERD in $<25 \%$ of GERD patients; 286 (33\%) physicians observed a rate of $25-50 \%$; $186(22 \%)$ a rate of $50-75 \%$, and $48(6 \%)$ a rate of $>75 \%$. More than half of physicians in Thailand stated that the proportion of NERD among GERD patients was $>50 \%$, whereas more than half of physicians in other countries said that the prevalence rate was of $<50 \%$. Statistical analysis revealed that the prevalence of NERD among GERD patients in Thailand was significantly high, while in Japan the prevalence rate was lower when compared with other countries.

The frequency of patients with Barrett's esophagus observed by physicians is shown in table 3 . More than half of physicians in all countries, except China, treated patients with Barrett's esophagus at a rate of $<1 \%$ of total 
Fig. 1. Number of cases of esophageal squamous cell carcinoma or esophageal adenocarcinoma encountered by each physician during 1 year. $\square$ = Esophageal squamous cell carcinoma; $\square=$ esophageal adenocarcinoma. Data represent the median at the 25 th and 75 th percentiles. ${ }^{*} \mathrm{p}<$ 0.01 versus other countries. ${ }^{* *} \mathrm{p}<0.01$ versus prevalence of esophageal squamous cell carcinoma within the same country.
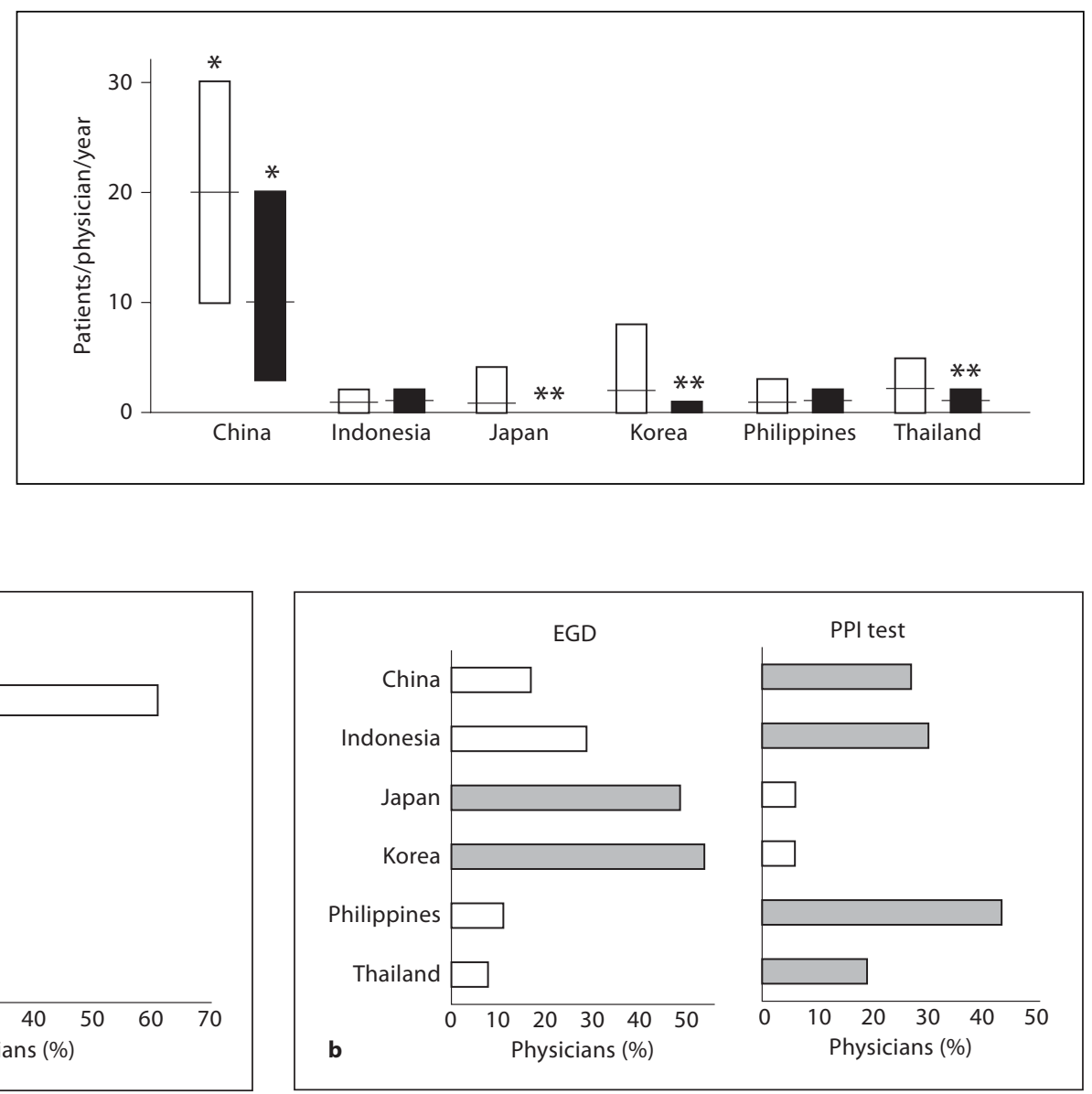

Fig. 2. Diagnostic tools used for the identification of GERD in East Asian countries. a Diagnostic tools used for the identification of GERD. b Diagnostic tools used for the identification of GERD, excluding the presence of GERD symptoms, in the East Asian countries shown.

patients, suggesting that Barrett's esophagus is more rare than GERD. In contrast, the prevalence of Barrett's esophagus in Chinese patients was significantly higher compared with other countries. Analysis of the subtypes of Barrett's esophagus indicated that long segmental Barrett's esophagus (defined as affecting $>3 \mathrm{~cm}$ of the esophageal length) was rare, since 750 (91\%) out of 818 physicians stated that only $<5 \%$ or $5-10 \%$ of the total patients with Barrett's esophagus were diagnosed with this subtype.

The number of cases of esophageal cancer encountered by each physician per year is shown in figure 1 . The number of cases of esophageal squamous cell carcinoma and adenocarcinoma in China was significantly higher compared with other countries. The incidence of esophageal cancer in the other five countries was low, accounting for a median of 1-2 cases per physician per year for squamous cell carcinoma and $0-1$ case for adenocarcinoma. In Japan, Korea, and Thailand, the incidence of esophageal adenocarcinoma was significantly lower compared with that of squamous cell carcinoma (fig. 1).

\section{Diagnosis of GERD and NERD}

The diagnostic tools used by physicians to identify GERD are shown in figure 2. The data show that most physicians (61\%) diagnose GERD based on symptoms, followed by esophagogastroduodenoscopy (EGD) (31\%), the PPI test (21\%), a questionnaire specific for GERD (such as QUEST; 10\%), pH monitoring (7\%) and impedance (3\%; fig. 2a). The presence of GERD symptoms was the most common diagnostic tool used in all countries. If we exclude diagnosis based on GERD symptoms, physicians in Japan and Korea preferred EGD, whereas those in other countries preferred the PPI test (fig. 2b). 
Fig. 3. First-choice drugs for the treatment of GERD. a Erosive esophagitis. b NERD. Values indicate the percentage of physicians that prescribed the indicated drugs for the treatment of GERD.

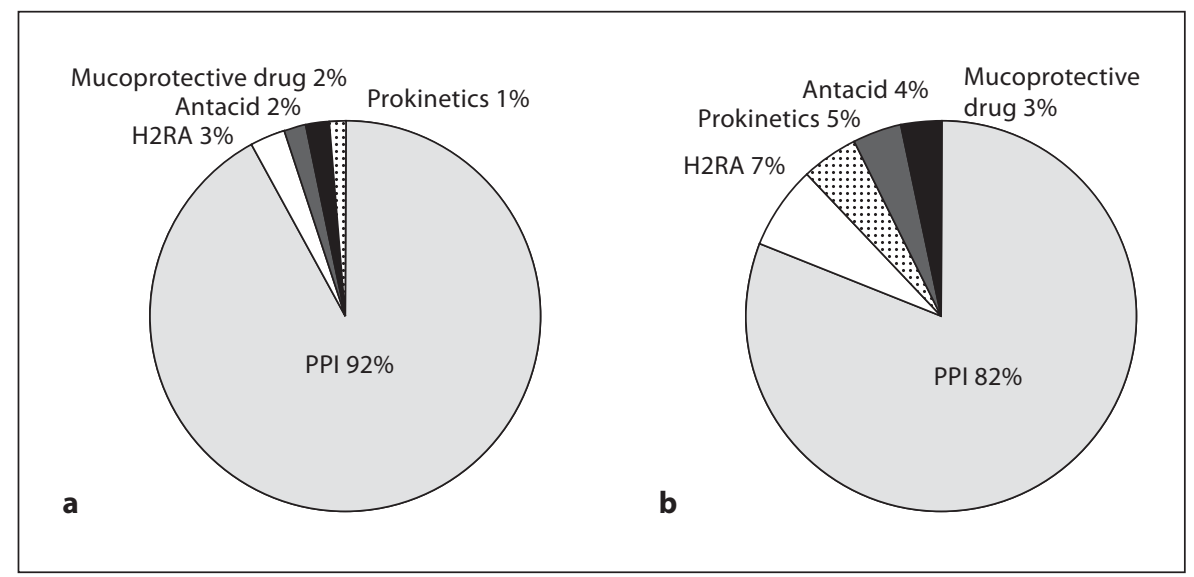

Table 4. Diagnostic tools used by physicians for the identification of NERD in East Asia

\begin{tabular}{lrlllll}
\hline & Total & $\begin{array}{l}\text { Negative } \\
\text { EGD } \\
\text { only }\end{array}$ & $\begin{array}{l}\text { Negative } \\
\text { EGD and } \\
\text { PPI test }\end{array}$ & $\begin{array}{l}\text { EGDative } \\
\text { pH study }\end{array}$ & $\begin{array}{l}\text { Negative } \\
\text { wGD } \\
\text { with biopsy }\end{array}$ & $\begin{array}{l}\text { pH- } \\
\text { imped- } \\
\text { ance }\end{array}$ \\
\hline China & 159 & $24(15)$ & $54(34)$ & $55(35)$ & $26(16)$ & $4(3)$ \\
Indonesia & 109 & $56(51)$ & $39(36)$ & $6(6)$ & $15(14)$ & $0(0)$ \\
Japan & 178 & $165(93)$ & $9(5)$ & $1(1)$ & $3(2)$ & $0(0)$ \\
Korea & 165 & $94(57)$ & $64(39)$ & $6(4)$ & $0(0)$ & $1(1)$ \\
Philippines & 143 & $74(52)$ & $50(35)$ & $17(12)$ & $4(3)$ & $2(1)$ \\
Thailand & 68 & $35(51)$ & $13(19)$ & $4(6)$ & $19(28)$ & $0(0)$ \\
\hline Total & 822 & $448(55)$ & $229(28)$ & $89(11)$ & $19(8)$ & $7(1)$ \\
\hline
\end{tabular}

Values indicate the number (\%) of physicians using the indicated diagnostic tools to identify NERD in each country.

Sixty-one percent of physicians stated that heartburn was the chief complaint of GERD patients, followed by acid regurgitation (41\%), epigastric pain (20\%) and chest pain (4\%). Heartburn was the most frequent chief complaint recognized by physicians in all five countries, but acid regurgitation was more frequent (47\%) than heartburn $(27 \%)$ in Korea.

The diagnostic tools used by physicians for the identification of NERD are shown in table 4. About half of physicians used EGD only, while others used a combination of EGD and other tools (e.g. PPI test, $\mathrm{pH}$ monitoring) for the diagnosis of NERD. Ninety-three percent of Japanese physicians made a diagnosis of NERD by negative EGD only, whereas $85 \%$ of Chinese physicians chose a combination of EGD and other tools for the diagnosis of NERD (table 4).

Survey of GERD and Related Diseases in East Asian Countries

\section{Treatment of GERD}

Figure 3 shows the first-line treatment used for erosive esophagitis and NERD. Most (92\%) physicians used a PPI as the first choice for erosive esophagitis (fig. 3a) and $82 \%$ of physicians chose a PPI for NERD (fig. 3b). In China, a relatively lower rate of physicians used a PPI as the firstchoice treatment for erosive esophagitis (75\%) and for NERD in both China (65\%) and Indonesia (75\%). Treatment of PPI-refractory erosive esophagitis and NERD is shown in figure 4 . Physicians chose increasing the PPI dose (53\%) or a combination of a PPI and other drugs (48\%), including prokinetics, H2RA and mucoprotective drugs, for the treatment of PPI-refractory erosive esophagitis (fig. 4a). Within Korea, the Philippines and Thailand, physicians preferred to increase the PPI dose versus using a combination of a PPI and other drugs as follows: 68 versus $28 \%, 63$ versus 50\%, 63 versus $39 \%$, for each respective country. In contrast, physicians in China, Indonesia, and Japan preferred to use a combination of PPI and other drugs rather than increasing the PPI dose as follows: 55 versus $40 \%$, 60 versus $54 \%$, 54 versus $39 \%$, for each respective country. Analysis of the treatment of PPIrefractory NERD indicated that the choice of increasing the PPI dose decreased, while use of antidepressant drugs increased compared with PPI-refractory erosive esophagitis (fig. 4b).

\section{Discussion}

The present study is the first to address various aspects of GERD. We provide a point-by-point discussion of the current guidelines, epidemiology, diagnosis, symptoms, and treatment for patients with GERD based on the re-

Digestion 2009;80:119-128 
Fig. 4. Treatment of PPI-refractory GERD. a Erosive esophagitis. $\mathbf{b}$ NERD. LARS = Laparoscopic antireflux surgery.

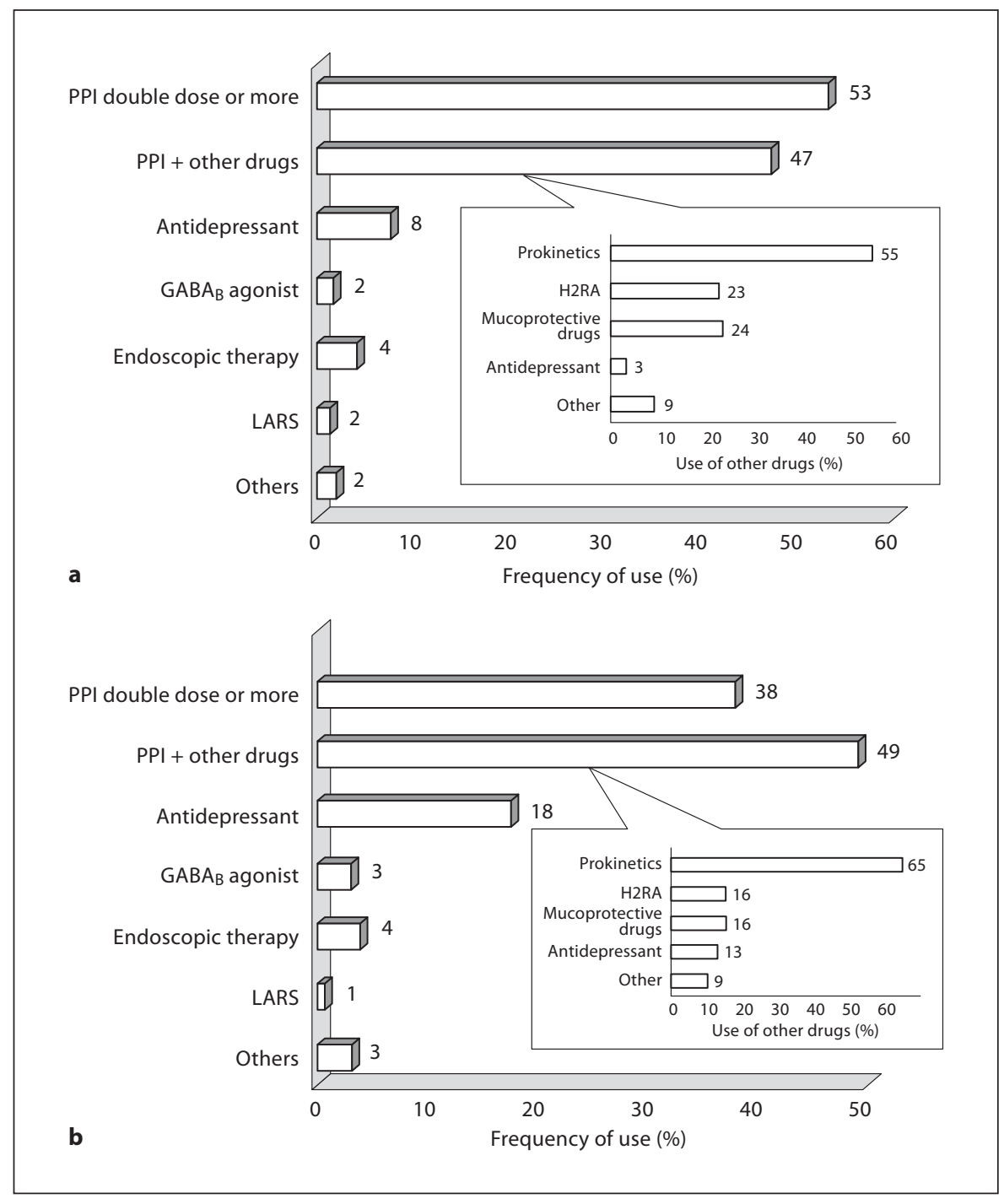

sponses of physicians in East Asian countries to a questionnaire-based survey.

The Asian-Pacific consensus [3], the Montreal definition [4], and the ACG guidelines [7] were the most frequently used guidelines in all countries, except Japan. The exact reasons why more than half of Japanese physicians did not use any guidelines for the care of GERD patients are unknown. Some possible reasons include the following: (1) that the GERD guidelines established by the Japanese Society of Gastroenterology will be published in spring 2009 (after the completion of this survey); (2) several international guidelines, except for the Montreal definition and the global consensus, are not translated into the Japanese language, and (3) Vakil et al. [8] reported that $9(18 \%)$ out of 49 Japanese primary care physicians used national guidelines established by the Japanese GERD society. The use of national guidelines was not provided as an option to answer in the present questionnaire, which may affect the lower rate of guideline use observed among Japanese physicians.

Several epidemiological studies have demonstrated that the prevalence of GERD is relatively lower in East Asia compared with Western countries, ranging from 2.5 to $6.7 \%$ of patients reporting symptoms of heartburn and acid regurgitation on at least a weekly basis [2, 9-14]; however, the prevalence of GERD in Asia is on the rise [5, $15,16]$. The present survey showed that in 2008 GERD was most common among patients treated by physicians in East Asia. In Japan, a relatively lower prevalence of GERD was observed, whereas a higher prevalence was 
observed in the Philippines; however, the precise reasons for these differences are unknown. It has been reported that $>60 \%$ of Asian patients with reflux symptoms do not present with erosive esophagitis, defined as NERD $[5,15]$. In fact, the proportion of NERD among Asian patients was found to be unexpectedly low in the present study. This result may be due to inadequate identification of NERD, particularly by physicians not specialized in this field.

The present study has demonstrated that the prevalence of patients with Barrett's esophagus, particularly the long segmental type, was low. This is further supported by several studies done in Asia which showed that the prevalence of Barrett's esophagus ranges from 0.06 to $0.22 \%$ in the general population [17-19], and $0.5-2 \%$ in patients with upper GI symptoms [5, 20-22]. Moreover, a study by the Japanese GERD society demonstrated that the prevalence of long segmental Barrett's esophagus, among the total number of patients with Barrett's esophagus, was $0.2 \%$ [23]. It should be noted that there is no uniform consensus between East Asian countries, as well as worldwide, on the definition of Barrett's esophagus and on the endoscopic confirmation of the gastroesophageal junction. Esophageal cancer, including squamous cell carcinoma and adenocarcinoma, was found to be higher in China. This may be due to greater participation of gastroenterologists in China. In addition, it is well known that China has the highest incidence of esophageal cancer in the world [24]. The other five countries showed a lower incidence of esophageal cancer compared with China. In Japan, Korea, and Thailand, esophageal adenocarcinoma was significantly lower compared with esophageal squamous cell carcinoma within the same country, suggesting a different pattern of epidemiology for esophageal cancers in Western countries [25, 26].

The most frequent tool used by physicians to diagnose GERD was the presence of reflux symptoms. This is reasonable given that EGD has low sensitivity of diagnosis due to the presence of NERD. Excluding GERD symptoms, there were differences in the use of other diagnostic tools among the countries investigated. Physicians in Korea and Japan preferred EGD, but those in other countries preferred the PPI test. This may be due to differences in the availability or ease of use of EGD in these countries, or because physicians in China, Indonesia, the Philippines, and Thailand consider the precise definition of GERD symptoms to be essential for the effectiveness of the empirical PPI test. Although there is no equivalent term for 'heartburn' in most Asian languages, and be- cause this term is poorly understood by $>80 \%$ of Asians [27], most physicians recognize heartburn as the chief symptom of GERD, followed by acid regurgitation. This finding suggests that most physicians rely on a detailed explanation of heartburn during medical interviews for the diagnosis of GERD. Only in Korea was acid regurgitation a more frequent (47\%) chief complaint than heartburn (27\%). This is further supported by a recent study of approximately 25,536 Koreans that showed that acid regurgitation is more common than heartburn in patients with GERD, particularly among women [28]. Similar findings were also observed in other Korean studies [2931].

There were differences between the countries in the tools used for the diagnosis of NERD. Overall, about half of physicians used only EGD, whereas the other half used a combination of EGD and other tools for the diagnosis of NERD. This pattern was mostly observed in Indonesia, Korea, the Philippines, and Thailand. However, a different pattern was observed among physicians in China and Japan. This may be due to differences in the concept or definition of NERD by physicians in each country. Most physicians who participated in this survey diagnosed NERD based on the presence of typical symptoms of reflux, including acid regurgitation and heartburn, and/or the relief of symptoms with a PPI (or H2-blocker) therapy. The definition of NERD is controversial. In addition, the definition of functional heartburn proposed by Rome III criteria [32] can also produce much confusion.

PPIs remain the 'gold standard' for therapy in the initial and long-term treatment of GERD $[3,4,7,33]$. The present study showed that most physicians use a PPI as the first-line treatment for erosive esophagitis. The reasons for the relatively lower rate of PPI use as the first-line treatment for NERD are unknown; however, one reason may be because some physicians consider NERD to be a mild form of erosive esophagitis. In PPI-refractory cases with erosive esophagitis, half of the physicians chose increasing the PPI dose, but others chose using a combination of a standard dose of a PPI in combination with other drugs (particularly prokinetics). The reasons why physicians in Korea, the Philippines, and Thailand preferred increasing the PPI dose, while those in China, Indonesia and Japan preferred a combination of a PPI and other drugs, are unknown. The low rate of laparoscopic antireflux surgery observed may be due to only a few surgeons participating in this survey. Among the countries studied, there were similarities in the treatment of PPI-refractory NERD. Compared with erosive esophagitis, the in- 
crease in the number of physicians who prescribed antidepressant drugs suggests that physicians recognize a link between esophageal hypersensitivity [34] or psychosomatic pathogenesis and PPI-refractory NERD $[35,36]$.

This study has some potential biases. First, there were differences in the number of physicians and the proportion of gastroenterologists that participated among the countries. The proportion of gastroenterologists in China was significantly high, with most physicians working at hospitals, while in the Philippines the proportion of gastroenterologists was significantly low. In addition, selection bias may have affected the present results. However, it is difficult to maintain all physician variables uniform (i.e. specialty, years of experience, and quality of institution where they work) because medical conditions are different in each country. Second, the present study relied on a questionnaire-based survey answered by physicians, so the data are not representative of the patient's perspective, particularly with respect to the epidemiology of GERD, Barrett's esophagus, and esophageal cancer. Given that this study was evaluated from a physician's perspective, the results reflect the practical patterns and processes of care for GERD patients, by physicians, in each country.

In conclusion, we present the first questionnaire-based survey analyzing GERD in East Asia. Similarities were found across the regions, such as in the percentage of GERD patients with Barrett's esophagus, the diagnostic tools used, the first-line treatment for GERD, and the treatment of PPI-refractory NERD. However, there were also differences with respect to the use of guidelines, the prevalence of esophageal cancer, the symptoms of GERD, the diagnostic tools used for NERD, and the treatment of PPI-refractory erosive esophagitis.

\section{Appendix}

Questionnaire used in the present survey.

Q1 Which guidelines do you use for care of GERD* patients? ${ }^{*}$ GERD includes erosive and nonerosive reflux disease (NERD).

1 Asian-Pacific Consensus (J Gastroenterol Hepatol, 2008)

2 Montreal Definition and Global Consensus (Am J Gastroenterol, 2006)

3 ACG guideline (Am J Gastroenterol, 2005)

4 Genval Workshop Report (Gut, 1999)

5 Others (please enter name)

6 None
Q2 How many patients with GERD do you treat? Please answer according to the percentage of total patients.

$1<10 \%$

$2 \quad 10-25 \%$

$325-50 \%$

$4>50 \%$

Q3 Among GERD patients, what is the percentage of NERD? $1<25 \%$

$2 \quad 25-50 \%$

$350-75 \%$

$4>75 \%$

Q4 How many patients with Barrett's esophagus do you treat? Please answer according to the percentage of total patients.

$1<1 \%$

$21-5 \%$

$35-10 \%$

$4>10 \%$

Q5 What is the percentage of long-segmental Barrett's esophagus $(>3 \mathrm{~cm})$ among Barrett's esophagus patients?

$1<5 \%$

$25-10 \%$

$310-25 \%$

$4>25 \%$

$5>50 \%$

Q6 How many patients with esophageal squamous cell carcinoma did you encounter during the last year? tients

Q7 How many patients with esophageal adenocarcinoma (Barrett's cancer) did you encounter during the last year? patients

Q8 How do you diagnose GERD? Please check most frequently used tool.

1 Symptoms

2 Questionnaire specific for GERD

3 PPI test

4 EGD

$5 \mathrm{pH}$ monitoring

6 Multi-channel impedance

Q9 What type of symptom do your GERD patients complain about?

1 Heartburn

2 Acid regurgitation

3 Epigastric pain

4 Chest pain

5 Others (enter symptoms)

Q10 How do you diagnose NERD? Please check the most frequently used tool.

1 Negative EGD only

2 Negative EGD and pH study

3 Negative EGD with biopsy

4 Negative EGD and PPI test

5 pH-impedance

Q11 What is the first-line treatment for erosive esophagitis?

1 PPI (standard dose)

2 H2RA

3 Antacid

4 Prokinetics

5 Mucoprotective drugs

6 Others (enter drug name) 
Q12 What is the first-line treatment for NERD?

1 PPI (standard dose)

2 H2RA

3 Antacid

4 Prokinetics

5 Mucoprotective drugs

6 Others (enter drug name)

Q13 How do you treat PPI-refractory erosive esophagitis?

1 PPI double dose or more

2 Combination of PPI and other drugs (enter drug name)

$3 \longdiv { \text { GABA } _ { \mathrm { B } } \text { agonist } }$

4 Antidepressant

5 Endoluminal surgery

6 Laparoscopic antireflux surgery

7 Others (enter treatment)
Q14 How do you treat PPI-refractory erosive esophagitis?

1 PPI double dose or more

2 Combination of PPI and other drugs (enter drug name)

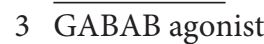

4 Antidepressant

5 Endoluminal surgery

6 Laparoscopic antireflux surgery

7 Others (enter treatment)

\section{Acknowledgements}

This study was sponsored by the IGICS, a keynote program of the Japanese Gastroenterological Association. We thank the physicians who participated in this survey.

\section{References}

$\checkmark 1$ Dent J, El-Serag HB, Wallander MA, Johansson S: Epidemiology of gastro-oesophageal reflux disease: a systematic review. Gut 2005; 54:710-717.

2 Wong BC, Kinoshita Y: Systematic review on epidemiology of gastroesophageal reflux disease in Asia. Clin Gastroenterol Hepatol 2006;4:398-407.

-3 Fock KM, Talley NJ, Fass R, Goh KL, Katelaris P, Hunt R, Hongo M, Ang TL, Holtmann G, Nandurkar S, Lin SR, Wong BC, Chan FK, Rani AA, Bak YT, Sollano J, Ho KY, Manatsathit S: Asia-Pacific consensus on the management of gastroesophageal reflux disease: update. J Gastroenterol Hepatol 2008;23:8-22.

-4 Vakil N, van Zanten SV, Kahrilas P, Dent J, Jones R; Global Consensus Group: The Montreal definition and classification of gastroesophageal reflux disease: a global evidencebased consensus. Am J Gastroenterol 2006; 101:1900-1920.

5 Wu JC: Gastroesophageal reflux disease: an Asian perspective. J Gastroenterol Hepatol 2008;23:1785-1793.

-6 Arakawa T, Fujiwara Y, Sollano J, Zhu Q, Kachintorn U, Rani AA, Hahm KB, Takahashi S, Joh T, Kinoshita Y, Matsumoto T, Naito Y, Takeuchi K, Yamagami H, Agustanti N, Xiong H, Chen X, Jang EJ, Furuta K, and IGICS study group: A questionnaire-based survey of prescription of non-steroidal antiinflammatory drugs by physicians in East Asian countries in 2007. Digestion 2009;79: 177-185.

7 DeVault KR, Castell DO; American College of Gastroenterology. Updated guidelines for the diagnosis and treatment of gastroesophageal reflux disease. Am J Gastroenterol 2005; 100:190-200.
8 Vakil N, Malfertheiner P, Salis G, Flook N, Hongo M: An international primary care survey of GERD terminology and guidelines. Dig Dis 2008;26:231-236.

9 Hu WH, Wong WM, Lam CL, Lam KF, Hui WM, Lai KC, Xia HX, Lam SK, Wong BC: Anxiety but not depression determines health care-seeking behaviour in Chinese patients with dyspepsia and irritable bowel syndrome: a population-based study. Aliment Pharmacol Ther 2002;16:2081-2088.

10 Wong WM, Lai KC, Lam KF, Hui WM, Hu WH, Lam CL, Xia HH, Huang JQ, Chan CK, Lam SK, Wong BC: Prevalence, clinical spectrum and health care utilization of gastrooesophageal reflux disease in a Chinese population: a population-based study. Aliment Pharmacol Ther 2003;18:595-604.

11 Watanabe Y, Fujiwara Y, Shiba M, Watanabe T, Tominaga K, Oshitani N, Matsumoto T, Nishikawa H, Higuchi K, Arakawa T: Cigarette smoking and alcohol consumption associated with gastro-oesophageal reflux disease in Japanese men. Scand J Gastroenterol 2003;38:807-811.

12 Wang JH, Luo JY, Dong L, Gong J, Tong M: Epidemiology of gastroesophageal reflux disease: a general population-based study in Xi'an of Northwest China. World J Gastroenterol 2004;10:1647-1651.

13 Fujiwara Y, Higuchi K, Watanabe Y, Shiba M, Watanabe T, Tominaga K, Oshitani N, Matsumoto T, Nishikawa H, Arakawa T: Prevalence of gastroesophageal reflux disease and gastroesophageal reflux disease symptoms in Japan. J Gastroenterol Hepatol 2005;20:26-29.
14 Cho YS, Choi MG, Jeong JJ, Chung WC, Lee IS, Kim SW, Han SW, Choi KY, Chung IS: Prevalence and clinical spectrum of gastroesophageal reflux: a population-based study in Asan-si, Korea. Am J Gastroenterol 2005; 100:747-753.

15 Fujiwara Y, Arakawa T: Epidemiology and clinical characteristics of GERD in the Japanese population. J Gastroenterol 2009;44: 518-534.

16 Ho KY: Gastroesophageal reflux disease in Asia: a condition in evolution. J Gastroenterol Hepatol 2008;23:716-722.

17 Kim JH, Rhee PL, Lee JH, Lee H, Choi YS, Son HJ, Kim JJ, Rhee JC: Prevalence and risk factors of Barrett's esophagus in Korea. J Gastroenterol Hepatol 2007;22:908-912.

$\checkmark 18$ Tseng PH, Lee YC, Chiu HM, Huang SP, Liao WC, Chen CC, Wang HP, Wu MS, Lin JT: Prevalence and clinical characteristics of Barrett's esophagus in a Chinese general population. J Clin Gastroenterol 2008;42: 1074-1079.

19 Wong WM, Lam SK, Hui WM, Lai KC, Chan CK, Hu WH, Xia HH, Hui CK, Yuen MF, Chan AO, Wong BC: Long-term prospective follow-up of endoscopic oesophagitis in southern Chinese-prevalence and spectrum of the disease. Aliment Pharmacol Ther 2002; 16:2037-2042.

-20 Wu JC, Sung JJ, Chan FK, Ching JY, Ng AC, Go MY, Wong SK, Ng EK, Chung SC: Helicobacter pylori infection is associated with milder gastro-oesophageal reflux disease. Aliment Pharmacol Ther 2000;14:427-432.

21 Yeh C, Hsu CT, Ho AS, Sampliner RE, Fass R: Erosive esophagitis and Barrett's esophagus in Taiwan: a higher frequency than expected. Dig Dis Sci 1997;42:702-706. 
-22 Rosaida MS, Goh KL: Gastro-oesophageal reflux disease, reflux oesophagitis and nonerosive reflux disease in a multiracial Asian population: a prospective, endoscopy based study. Eur J Gastroenterol Hepatol 2004;16: 495-501.

23 Kohno T, Kozu T, Ohara S, Kusano M: The prevalence of Barrett's mucosa in the Japanese. Gastroenterol Endosc 2005;47:951961.

24 Boffetta P: Oesophageal cancer; in Stewart BW, Kleihues O (eds): World Cancer Report. Lyon, World Health Organization/International Agency Research on Cancer, 2003, pp 223-227.

-25 Blot WJ, Devesa SS, Kneller RW, Fraumeni JF Jr: Rising incidence of adenocarcinoma of the esophagus and gastric cardia. JAMA 1991;265:1287-1289.

26 Blot WJ, McLaughlin JK: The changing epidemiology of esophageal cancer. Semin Oncol 1999;26(suppl 5):2-8

-27 Spechler SJ, Jain SK, Tendler DA, Parker RA: Racial differences in the frequency of symptoms and complications of gastro-oesophageal reflux disease. Aliment Pharmacol Ther 2002;16:1795-1800.
28 Shim KN, Hong SJ, Sung JK, Park KS, Kim SE, Park HS, Kim YS, Lim SH, Kim CH, Park MJ, Yim JY, Cho KR, Kim D, Park SJ, Jee SR, Kim JI, Park JY, Song GA, Jung HY, Lee YC, Kim JG, Kim JJ, Kim N, Park SH, Jung HC, Chung IS, The H. pylori and GERD Study Group of Korean College of Helicobacter and Upper Gastrointestinal Research: Clinical spectrum of reflux esophagitis among 25,536 Koreans who underwent a health check-up: a nationwide multicenter prospective, endoscopy-based study. J Clin Gastroenterol 2009, Epub ahead of print.

29 Jeong JJ, Choi MG, Cho YS, Lee SG, Oh JH, Park JM, Cho YK, Lee IS, Kim SW, Han SW, Choi KY, Chung IS: Chronic gastrointestinal symptoms and quality of life in the Korean population. World J Gastroenterol 2008;14 6388-6394.

30 Cho YS, Choi MG, Jeong JJ, Chung WC, Lee IS, Kim SW, Han SW, Choi KY, Chung IS: Prevalence and clinical spectrum of gastroesophageal reflux: a population-based study in Asan-si, Korea. Am J Gastroenterol 2005; 100:747-753.

31 Yang SY, Lee OY, Bak YT, Jun DW, Lee SP Lee SH, Park GT, Yoon BC, Choi HS, Hahm JS, Lee MH, Lee DH: Prevalence of gastroesophageal reflux disease symptoms and uninvestigated dyspepsia in Korea: a population-based study. Dig Dis Sci 2008;53: 188-193.
2 Galmiche JP, Clouse RE, Bálint A, Cook IJ, Kahrilas PJ, Paterson WG, Smout AJ: Functional esophageal disorders. Gastroenterology 2006;130:1459-1465.

33 Chiba N, De Gara CJ, Wilkinson JM, Hunt $\mathrm{RH}$ : Speed of healing and symptom relief in grade II to IV gastroesophageal reflux disease: a meta-analysis. Gastroenterology 1997;112:1798-1810.

34 Nagahara A, Miwa H, Minoo T, Hojo M, Kawabe M, Osada T, Kurosawa A, Asaoka D, Terai T, Ohkusa T, Sato N: Increased esophageal sensitivity to acid and saline in patients with nonerosive gastro-esophageal reflux disease. J Clin Gastroenterol 2006;40:891895.

35 Fass R: Erosive esophagitis and nonerosive reflux disease (NERD): comparison of epidemiologic, physiologic, and therapeutic characteristics. J Clin Gastroenterol 2007;41: 131-137.

36 Fass R, Sifrim D: Management of heartburn not responding to proton pump inhibitors. Gut 2009;58:295-309.

37 An evidence-based appraisal of reflux disease management - the Genval Workshop Report. Gut 1999;44(suppl 2):S1-S16. 